Billett, S (in press 2006) Exercising self through working life: Learning, work and identity In A Brown, S Kirpal \& F. Raumer (Eds) Identities at work. Springer, Dordecht, The Netherlands

\title{
Exercising self through working life: Learning, work and identity
}

\author{
Stephen Billett, Griffith University, Australia
}

\section{Summary}

This chapter discusses what motivates and directs individuals' lifelong learning. It proposes that individuals' sense of self shapes and is shaped by their participation and learning throughout working life through a quest to become themselves. In encouraging individuals to 'help themselves' in their learning throughout their working life, this learning is likely to be driven by personal intentions and their agency rather than the goals of others. Therefore, the agency and intentionality that directs that quest may not always coincide with the kinds of goals that government and employers want. Instead, helping oneself is likely to be directed by and towards their sense of self, which includes the negotiation of identity as they engage in work. It follows that in understanding the processes of learning and the remaking of work practice, a greater acknowledgement of individuals' sense of self needs acknowledging and to be accounted for in policies and practices associated with lifelong learning. Policy and policy-related initiatives might need to account for factors that motivate and engage individuals in the process of learning throughout working life and not assume that goals beyond the individual will be sufficient for mobilising that learning.

\section{Part I: Learning, self and work}

\section{Exercising self through working life}

This chapter seeks to understand how individuals engage in and learn through work and throughout working life, for what purposes and how they are motivated to learn effortfully. Without such an understanding there can be little certainty about whether the expectations placed on individuals by government and employers about individuals' helping themselves will be fulfilled, in the ways they intend. So it is important to know more about how individuals participate in and learn throughout their working life, how they exercise their agency in participating in and learning through work, and for what purpose and how these are linked to their values and beliefs. In short, what is it that directs individuals' learning throughout working life? In what ways will the goals of government, industry groups and enterprises likely to be achieved through the actions of workers as actors and learners.

It is advanced here that an individual's sense of self and its exercise through her or his agency and intentional acting does much to direct and shape this learning and also the ongoing remaking of the practices enacted at work. It proposes a greater acknowledgement and consideration of the interdependence between individual and social agency of employees, not just the actions of employers and government. This is warranted within current conceptions of learning throughout working life and, in particular, the role of individuals' quest to 'be themselves'. This quest includes the re-shaping of that sense of self as individuals participate in and remake their work practice (Billett, Smith \& Barker 2005; Billett \& Somerville 2004). This may well lead to contradictions and complexities among the intentions of governments, employers and individuals. The contributions of both social agency, in the forms of suggestion provided through societal cultural practices and norms, the complex of social factors comprising 
the situated experiences of the workplace, and also individual agency, in the form of intentions, gaze and engagement, are held to be interdependent. There is mutual reliance or interdependence between these contributions for sustaining their respective continuities and development in the remaking and transformation of the cultural practices that constitute paid work and in the development of individuals' capacities or learning. Central to both of these forms of continuity and their interdependence, yet less understood and acknowledged, is the agentic and transformative role of self as an element of identity in forming and energising this interdependence. To explore, illuminate and understand further this interdependence, a study of five individuals working life and life outside of work is discussed.

This study sought to identify bases of engagement by individuals in their working lives and the role played by their agency, intentions and sense of self in their work and learning within their working lives (Billett \& Pavlova 2005). Each of these five individuals confronted significant change at work and with their work during the period of the investigation. It found that, against expectations, in each instance these individuals' exercise of their agency and intentionality was directed towards 'being themselves', as they negotiated their place in changing work environments and work tasks. For four of the five, these actions and negotiations lead to improving, supporting or easing their standing in the workplace. In the fifth instance, it was not a lack of workplace support as much as the over exercise of agency that resulted in a less than satisfactory outcome. By different degree, for each worker, there was evidence of interdependence between their needs and the affordances of the workplace, but with the negotiations directed by their agency and goals. While governments are expecting individuals to be responsible for their own lifelong learning and helping themselves (Edwards and Boreham, 2003), the learning may not be directed in the ways that government and their employers envisage. So there may be inconsistencies among what individuals, employers and government want to arise from this helping themselves, because it is directed towards personal goals, albeit negotiated and reshaped through working life experiences. This suggests that policies and practices associated with aiming to secure particular kinds of working life outcomes need to be considerate of or consonant with individuals' agency in securing their sense of self. This includes the negotiation between the individual and the workplace in transforming and reshaping that sense of self. The conceptual premises and their embodiment in data about individuals' working lives are used to argue that while governments, education institutions and workplaces are keen to mobilise workers as learners throughout their working lives to serve economic and civic purposes (Field, 2000), such mobilisations are inevitably mediated though individuals' sense of self and intentions: their agency. These need accounting for in consideration of policy and practice.

To elaborate these propositions, this chapter initially outlines and discusses the relational interdependence between social and individual agency as a means to understand learning through and for work, and the role that individual agency and subjectivities play in that interdependence. Following this, the procedures for, participants in and findings of a study that investigated the five workers' working lives are described. The findings are elaborated in sections that discuss the alignments among the changing work of these individuals and their interests and intentions. It also elaborates, how individuals' goals, preferences and intentions are intertwined with their work and working life and the central role of their personal agency in shaping how they work and the interdependence between the changing nature of work and their 'sense of self'.

\section{Learning throughout working life in times of change}

Interest in learning through and for work seems to be on many minds at the moment. Much of this interest is motivated by government, industry and enterprise concerns about the availability and level of skills within national, industry sector and enterprise workforces and maintaining or developing these workforces through times of changing demand and requirements for workplace 
competence. Yet, while focusing on a common concern about the levels and quality of workplace skills, the goals of government, industry, enterprises and individuals and their preferred means to address these goals may be quite different and even divergent. Governments are interested in the provision of a workforce that can adapt to changing demands of an increasingly globalised and uncertain economic environment and can also resist unemployment (Green, 2001). Industry representatives and leaders are likely to be primarily concerned about the maintenance and development of skills for that industry sector, which includes competing for public funds for educational provision, for instance, against other sectors. Enterprises are more likely to be concerned with the specific set of skills required for the continuity and development of their products and services. Individuals may be most concerned about their continuity of employment or progression along a career path.

These different purposes lead to distinct acts of agency. For governments, the aim seems to be to mobilise individuals to participate energetically and resourcefully in a global competition against counterparts in other countries (Field, 2000). This mobilisation is to be focused on individuals taking responsibility for their own learning — helping themselves — with government enabling their engagement rather than providing (Edwards \& Boreham, 2003). Industry groups develop skills standards, develop and endorse courses to generate industry-specific skills and arrangements for their certification. They also implement schemes to attract or retain workers in the sector and identify skill shortages and relay these concerns to government. Depending upon their needs, enterprises might act to encourage or restrict training opportunities, facilitate enterprise specific certification, engage with national schemes or not bother with either. Enterprises also elect how they distribute and expend their resources for employee development, and often in ways impervious to government mandate (Brunello \& Medio, 2001). They may deny more portable skill recognition and will likely not accentuate the complexity of the work to be learnt (except in advertising their wares), lest this be used to undermine the enterprises' capacity to control their labour costs. More than a lack of consonance, there are also contradictions in these distinct actions. The strategic goals of government may not always be consistent with those of the industry sector. Similarly, enterprises, where the engagement in and learning from work occurs, may have different priorities from those of both government and the industry sector. Somewhere in here sits the individuals whose role in achieving any of these goals is central to their success, yet whose contributions appear to remain misunderstood and/or under acknowledged.

And therein lays a key problem. These diverse and contradictory goals and processes may well misunderstand and underplay the role of the individuals, who are to be subjected to them. They seem to downplay the likelihood of individuals having their own interests and intentions, which may or may not coincide with others goals and concerns (Billett, Barker, \& HernonTinning, 2004). So there may well be contradictions between individuals' goals and those of government, industry groups, and their employers, which may be exercised when they help themselves. This can lead to negotiated, and possibly contested, bases for interaction between individuals and the intents of their workplaces (Billett, 2001), industry or government (Billett, 2000). Individual interest and engagement is far from a secondary or peripheral consideration. Because of its role in learning and remaking of work practices, individuals' sense of self, their agency and intents are central to the prospects for government, industry and enterprises ever achieving their goals.

More than learning through their participation in work, individuals also actively engage in the remaking of the kinds of participation, vocational practice and skilled performance that governments, industry groups and enterprises seek to secure. How individuals elect to be mobilised through the exercise of their agency to secure governmental goals, engage with 
industry-designated attributes of their work, and enterprises' priorities are in some ways personally dependent. In part, they are an outcome of individuals' construal of, engagement with and construction of these goals and their associated practices in their working lives (Billett, 2005b). Yet, what initiates and directs individuals' learning throughout working life and the role that individuals' agency and intentions play, their consequences for their workplaces and the strategic goals of industry and government are far from being fully understood. Central to elaborating this understanding is individuals' sense of self.

\section{Working, learning and identity}

Work is a key element of adult life and, for many individuals, it is the means through which their identity is shaped and exercised (Noon \& Blyton, 1997; Pusey, 2003). So more than engaging in work being solely about exchanging time and labour for remuneration, there are potentially important outcomes for individuals that arise from engaging in work activities and interactions. The salience of work to individuals' identity appears also to be more than positioning within different socially privileged forms of work. If this were the case, presumably only those employed in the most prestigious and highest-paid jobs would enjoy any sense of fulfilment in their work. The rest would be disillusioned and disempowered by their relative standing on such an externally mediated measure. Yet, workers engaged in what many would classify as low status and lowly paid work have been shown to exercise significant agency and pride in their work, and in ways associated with localised recognition and personal satisfaction (Billett, 2003a). This suggests powerful personal motivations for participation in work that might not be highly regarded in the wider community. One way to understand the importance of and links between self and work is that the process of engagement in activities is central to ongoing and moment by moment individual learning (Rogoff, 1990). The engagement in work of any kind leads to particular and possibly significant legacies in terms of individuals' development, in ways that are generative of close links between individuals' sense of self and their work. Consequently, work and learning are so intertwined as to almost inevitably link individuals to their work activities in some way.

Concepts, procedures and values are often learnt, reinforced and transformed through engagement in work activities. The workplace provides an environment that is rich in its contributions to individuals' learning as they engage in work activities and, in doing so, remake the cultural practices that comprise paid work (Hodkinson \& Hodkinson, 2003; Somerville \& Bernoth, 2001). The privileging of environments in which learning takes place should not be according to whether they are sites claiming to promote learning as their key purpose. Instead, it should be according to the degree to which they provide the inter-psychological experiences of activities and interactions that underpin substantive learning. It is through these that knowledge is experienced, accessed, engaged with and constructed. Development of knowledge and understanding is perhaps most effectively achieved when supported by the assistance of a more experienced partner who understands that knowledge and can make accessible what is otherwise inaccessible, and support and monitor learning and development (Billett, 2005a). Such affordances or invitational qualities are central to what constitutes a learning environment.

Nevertheless, central to this process of learning and what constitutes a learning environment is also the degree to which individuals act agentically in the process of constructing knowledge (Billett, 2005b). This epistemological agency likely comprises individuals' construal of what they experience (e.g. what constitutes welcome or unwelcome affordances), the degree of, and intent in, their engagement with those affordances (e.g. activities and interactions) and their construction of meaning, procedures and values. This process is shaped by and premised upon individuals' agency, through the focus and expenditure of conscious thought and action, and their intents - the particular focus and direction of that agency. These processes are shaped by 
individuals' sense of self and their subjectivity: how they view the world. The concept of individuals' gaze can be seen as a metaphor for the enactment of a sense of self and subjectivity. It is this gaze that shapes how individuals construe and construct the immediate experience they encounter in workplaces. So individuals' learning, albeit the refinement of what is already known or its reinforcement, arises through their engagement in everyday conscious thought through what constitutes their personal epistemology (Bauer, Festner, Gruber, Harteis, \& Heid, 2004; Smith, 2004), notwithstanding that epistemology is itself being shaped iteratively and relationally through a history of engagements with the social world.

Transformational learning can also arise through engaging in new activities and interactions. These are particularly plentiful in turbulent times of employment, or when other experiences confront individuals with perturbations requiring new insights (Rogoff, 1990), novel procedures or diverse values (Somerville, 2002). These learning processes have parallel and analogous consequences for the cultural practices that comprise paid work. That is, as individuals engage in even the most routine form of learning they are participating in the active process of remaking cultural practices. Culture and society are remade and transformed as individuals engage with their practices, learn and construct them at particular points in their personal histories and points in time as they engage with a battery of social suggestions and norms (Billett \& Somerville, 2004). It follows that central to individuals' learning and their remaking of culture is the degree to which their agency directs, engages and constructs what they experience: their epistemological agency which both shapes and is shaped by their sense of self (Billett \& Pavlova, 2005). Consequently, both continuities and transformations in work and individuals' learning are linked to how individuals construe, engage in and construct the activities and interaction that comprise the historical, cultural and situational contributions that collectively constitute the gift of the social (Archer, 2000): that is, the norms, values and practices that are accessible in and projected by the social world.

\section{Interdependence between social suggestion and individual agency}

So there is interdependence between both individual and social agency in the dual processes of two kinds of change: individuals' learning and remaking culture. Given this relational interdependence between the social (e.g. geneses of subjectivities, cultural demands and situational requirements) and individual (e.g. intentionality and agentic action) contributions to thinking and acting, and therefore learning (e.g. Valsiner \& van der Veer, 2000), individual agency and intentionality play central roles in both kinds of change.

The key premise behind this relational interdependence is that neither the social suggestion nor individuals' agency alone is sufficient to enact the desired learning and the remaking of the cultural practices that constitute work (Billett, 2005b). The social suggestion or press of the social comprises societal norms, practices and values, and their enactment, albeit shaped by local factors in particular ways. However, this press or suggestion is unlikely to ever be complete or comprehensive enough in workplaces to secure complete socialisation: the unquestioned and unquestionable transfer of knowledge from the social world to the individual. As Newman, Griffin and Cole (1989) propose, if the social world was able to extend its message so unequivocally, there would be no need to communicate. This is because understandings would be implicit, not requiring further communication to be construed and comprehended. However, as Berger and Luckman (1967) and others propose, the social suggestion is not amplifiable in ways that lead to complete socialisation, because individuals engage with the suggestion with greater or lesser reception. For no other reason, because of the limits of the social suggestion, individuals have to be agenetic and active in the construction of meaning. Meaning and practices arising from the social world require interpreting and construing. Yet, even beyond simply attending to, engaging with and comprehending what is being suggested, importantly individuals also bring 
possibly unique bases of conceptions, procedures and values to their engagement with social forms and practices. These considerations lead to some premises for the central role of self in the learning of and remaking cultural practices that comprise work.

So, the first premise is that there is an inevitable and important interdependency between the agency of the social world in projecting or pressing its suggestion and that of the individuals in making sense of what is suggested to or afforded them. This is particularly salient for learning the cultural practices that constitute paid work. Much vocational knowledge has its origins in cultural practices and historical precedents (Scribner, 1985). This genesis is important because it arises from a cultural need and has been refined over time through enactments of the practices. Consequently, to access this knowledge with its historical and cultural legacy requires engaging with the social world, as this knowledge does not arise from within the individual. Rather when individuals engage with this knowledge and reconstruct it, in addition to their individual development, they are also remaking these cultural practices at a particular point in time and through particular relationships to the social suggestion.

From the ideas advanced above, the remaking of cultural practice and individual learning is not through some faithful process of reproduction. Instead, there is a remaking through individual's engagement with and construction of those practices, albeit mediated by the exercise of social and cultural norms and practices whose needs have to be met at particular points in time in individuals' personal histories. Moreover, the exercise of this personal agency is essential in transforming cultural practices as new cultural needs arise, such as those brought about by changing times or technologies. Wertsch (1998) distinguishes between mastery (i.e. compliant) learning and appropriation. Compliant learning is superficial and may well be the product of forceful or compelling social suggestion of the kind which Valsiner (1998) identifies.

Appropriation is the socially derived learning in which individuals engage willingly that leads to a concurrence between what is experienced and individuals' values and beliefs. In this way, compliant learning may be superficial or appropriated depending upon the degree to which they are aligned with individuals' beliefs and values. Given that richer or deeper kinds of learning likely require effortful engagement buoyed by interests and intentionality (Malle, Moses, \& Baldwin, 2001), this kind of learning may arise more frequently when it engages individuals' interests and agentic action.

The second central role of individuals' agency in learning and the remaking of culture is that there is likely to be some degree of person-dependence in these processes. Individuals' construal of what they encounter is socially shaped, through a personally unique set of negotiations with the social suggestion, in a way that comprises their organic growth or life histories. These negotiations are encountered continuously through the myriad forms of social practices that individuals engage in throughout their lives that contribute microgenetically moment-by-moment — to their ontogenetic development. From the earliest age, those processes that Piaget (1968) referred to as securing equilibrium, and more recently von Glasersfeld (1987) refers to as maintaining viability, comprise an enduring personal epistemological venture. As well as confronting novel experiences, individuals' construals are premised on an expectation of variability and inconsistency in the response from the social world as well as aspects of certainty and consistency. For instance, Baldwin (1894) noted that from the earliest age, children learn to expect inconsistency in their dealings with the social world. He notes how a request for a biscuit will be fulfilled on one day, but rejected on the next, by the same person. In this way, individuals' ontogenetic development arises through a personally agentic epistemological process that is shaped through ongoing interactions with the social world, whereby individuals come to expect and therefore monitor for inconsistency. In turn, this process subsequently influences how they engage with new experiences. These experiences are likely to be in some ways unique to 
individuals, are highly formative in ways that Vygotskians describe as inter-psychological, and link to intra-psychological attributes. As a consequence there will inevitably be personally distinct conceptions as well as areas of commonality or shared understanding with others in their process of knowledge construction and remaking of cultural practices (Billett, 2003b).

The third premise then is that, because of the ontogenetic legacy and personal epistemology, consideration needs to be given to a consideration of individuals' pre-mediate experiences - those that come earlier and, in turn, shape subsequent construals. These construals shape their conceptions and subjectivities — gaze, if you like — and, consequently, how they construct subsequent experiences. It is these conceptions and subjectivities that shape individuals' intentionality and agency in the processes of their learning and the remaking and transformation of cultural practices. Because these pre-mediate experiences are themselves shaped by, yet contribute to, unique personal epistemologies, even the most apparently uniform social experience, which affords its contributions seemingly equally to all parties, will be the subject of a partly individualised process of interpretation, construal and construction. This leads to particular and possibly unique personal kinds of epistemological bases, albeit that they are socially shaped. So life histories comprising individuals' prior social experiences stand as an important premise on to how they engage with the contributions of the social that they encounter in the immediate experience (i.e. workplace activities and interactions).

The final premise is that the relationship between individual and social agency is not mutual or reciprocal, it is relational. Just as the social suggestion can be either weaker or stronger, so too can be individuals' engagement with a particular social suggestion (e.g. situated practice, cultural norm or cultural practice). The prospects for the coming together and contributions of the individual and social being enacted in equal parts or ways that are equally shared is quite remote. The very interactive processes arising will be individually unique in some ways, and individuals may be selective in their reading of a particular social suggestion or simply be unaware of it (Billett 2005b). So central to issues of the interdependence between social and individual agency is the fact that it is rendered relational as individuals encounter social experiences projected in multitudinous and diverse forms and construct meaning through ontogenetically diverse bases.

So this relational interdependence is continually being negotiated between both social and individual intentions, and their relations are transformed. Within these ongoing negotiations a key role is the agentic exercise of individuals' sense of self or identity. Rose's (1990) concept of the 'enterprising self' provides an instance of this kind of agency. Here, the focus and direction of the individual, as an entrepreneur, is towards self-regulation and individualisation aimed at securing the employer's economic goals and, therefore, securing their relations as an employee. Yet, an inherently individually constructed set of intentions may also be characterised by resistance to or the clever manipulation of the regulatory practices of the workplace (Grey, 1994), as much as either unquestioning compliance to them or their expedient reproduction in the self. That is, the exercise of agency may not always be directed towards securing further social subjugation or faithfully reproducing existing subjectivities. Instead, it may focus sharply on securing more personal goals.

\section{Appraising the individual within interdependencies at work}

In emphasising the individual and granting their agency as being distinct from the social experience, the issue arises of on what bases should individual agency be evaluated. Through a privileging of individual agency and intentionality the risk of a different kind of relativism emerges, that of the 'anything goes' kind. So beyond acknowledging the descriptive and personal-dependent phenomenological construction of self, there is a need to identify bases from which to discuss and evaluate the role of individual agency and intentionality in and for work. 
Social forms advance an objective valuing of work, which while flawed, reflects particular views of privilege and elitism (Wright Mills, 1973), and provides a basis for critique and evaluation, which is less easy from within a highly individualistic or personal-dependent form. For instance, such an objective account of what constitutes worthwhile work might be premised on benefits to the individual in terms of pay or advancement to higher status and paid positions. Of course, it is possible to propose that whatever the self in work means to individuals should suffice. However, some commentators would be quick to suggest that individuals are being duped into false consciousness (Ratner, 2000) or an incomplete or unsatisfactory sense of self. O'Doherty and Willmott (2001) hold that individuals are entangled with the social world and that they are working to identify a 'sense of self' in their work. Given the negotiated relationships between individuals and workplaces, and the need for individuals to engage in practices constructed by others, they propose it is more useful to view personal agency in terms of individuals securing a 'sense of self' within contested and negotiated relations. Even when able to exercise high levels of freedom, this offers a device for individuals to secure a sense of well-being and satisfaction that is associated with the goals of the work, rather than the allegedly more problematic humanistic conception of individual agency of 'being themselves' (ibid., p.117).

So, a starting point for an evaluation of individual agency might be the capacity of individuals to negotiate and construct a 'sense of self' from what is encountered, rather than 'being oneself', which is held to be unrealistic in such socially saturated times (Gergen 2000). This does not imply some chaotic privileging of a highly individualised epistemology. Instead, it reflects a constantly shifting and uncertain foundation of what comprises the self, but implies being agentic in securing a sense of self. This suggests interactions between the individual and the workplace are negotiated, contested and above all are highly relational. It follows that individuals may attempt to construct a sense of self within the socially-derived constraints of their work.

It follows that as work requirements and the means of participation in work are transformed, there are direct consequences for individuals' subjectivities and identities, and possible renegotiation of the self. Understanding these consequences may be enriched through a consideration of the enactment of individuals' agentic action. In this way, learning throughout working life can be viewed as a transformative journey as individuals selectively negotiate their engagement in work, and with changing work requirements, work practices and the shifting bases for participation in work. Throughout, individuals' identity, subjectivities and actions will likely be subjected to selective, yet contested, and interdependent engagement.

\section{Part II: Relations among work, identity and learning}

\section{Studying self, learning and work}

The investigation described and discussed here attempted to identify the bases by which five individuals engage in their working lives and what guides their practices and decision-making. The data gathering comprised a series of sequenced tape-recorded conversations with the participants during a series of semi-structured interviews. The initial interviews were used to identify what constituted the work of these five individuals, through an analysis of their work activities and interaction, and then their personal histories including their working lives. These initial interviews were followed by conversations occurring every two months over the next twelve months. They were used to elicit data about work, working life, life outside work and transitions in working life. The aim here was to map changes in working life, subjectivity and decision-making over the twelve-months period. Specific questions were used to elicit data and refine and extend it beyond the initial analyses. The analysis included identifying the trajectories 
of participants' working lives and life outside of work. To appraise, verify and validate initial analyses, the data from each interview and its initial analysis and deductions were discussed with participants in subsequent interviews. A key concern of the investigation was to continue the conversations through a process of refinement and extension of data over a yearlong period.

\section{Five workers}

The selection of the five participants was premised by a concern to include individuals engaged in different kinds of work (e.g. technically mediated), modes of engagement with work, and with diverse work histories (e.g. migrant, part-time worker). There was, however, no attempt to select participants who were well positioned to exercise personal and autonomous agency. The participants were as follows. Carl arranges insurance quotes and sells insurance to customers working on a commission-only basis as a broker for a large national insurance brokerage company. He is essentially a sole operator business within a large enterprise. Ken is a manager of an information and communications technology unit within a corporatised state government department. His unit has particular responsibilities for electronic security across the department. Lev is an electronics engineer working in a large multinational corporation that designs and manufactures rail transportation systems. Lyn works part-time in a wholesaling business in the metropolitan fruit and vegetable market, as a member of small team of workers. Commencing at 2:00 a.m., she works two or three days a week, continuing until the day's orders are complete and dispatched. Mike works as a supervisor and customer service coordinator in a large motor vehicle dealership, working with the workshop and sales departments and with customers. He is a car mechanic by training and extensive practice. Collectively, these five individuals engage in diverse forms of work embracing different kinds of performance requirements and means of engaging in work.

Diverse and circuitous routes are common to each of these five individuals' working lives. Carl, the insurance broker, was a professional sportsman before retiring and developing a career in insurance brokering. So there is significant discontinuity between his original and current career. Ken, the manager of an information technology unit, grew up in and remains part of a Christian community. His first work experiences were church-related activities. After this, he worked in a range of service-oriented occupations (e.g. retail, restaurant management, pest eradication) before developing expertise with electronic security systems. It was through this expertise that he eventually became the manager of an information technology unit within a recently corporatised government department. Lev, the electronic engineer, learnt his electronics skills through a structured program of study during service in the Russian military. Later, he was employed as an electronics engineer in the Russia railway system. However, upon migrating to Australia, because of low levels of English language proficiency, he had to find employment in work that he described as being menial and demeaning (e.g. hospital night time orderly). Only when his English language competence improved was he able to secure employment in electronics. Lyn, who works in the fruit and vegetable market, had worked in forms of employment that would be classified as being low-skill and low paid (e.g. retail work, detailing cars in sales yards and factory work) while continuing to be the sole parent and provider for her three children. Mike's move into a supervisory role is relatively recent in the dealership in which he works. He had worked as a motor mechanic, throughout his working life. However, he had spent much of that time as a road-side service mechanic assisting motorists whose vehicles had broken down, which is quite different work than being in an automotive workshop.

So, of the five participants, only Mike has had a continuous vocational focus as a car mechanic, although his interests in customer servicing saw him engage in roadside emergency assistance work. The others, by different degree, have experienced discontinuities or transformations in their working lives and occupational identities. For Lyn, who works part-time 
in the fruit market, unlike the others, that work identity still remains unclear, uncertain and immature. Yet, she is quite intentional in working to transform her identity from that of a caregiver to her children to that of a worker. These diverse and meandering working life trajectories suggest that lifelong learning and learning throughout working life are focused on more than the development of skills. These processes also included the making and remaking of occupational identities and subjectivities through uncertain pathways that comprise these individuals' work life histories. As will be elaborated below, each pathway is marked by evidence of intentions and the exercise of their agency in attempts to secure those goals. Noteworthy in these pathways is the contrast with the linear developmental journey that was advanced by Erikson (1968). Rather than negotiating psycho-social crises that were primarily sourced within individuals as they negotiate their sense of identity and worth at socially sanctioned life stages, these five workers' trajectories emphasise the need to secure their sense of identity or self through disruptive and uncertain working lives. To understand the context in which these negotiations occurred, it is helpful to elaborate the changes to work and work practices and their consequences for these individuals.

\section{Changing work}

There was transformation and change in each individual's work and work requirements in recent times, including during the yearlong data gathering period. Yet, instead of being disruptive and disarming or marginalising, as some accounts predict (e.g. Bauman, 1998; Beck, 1992; Rifkin, 1995), these five individuals largely adapted well to the transformation in their working life. Further, rather than being an impediment, in some instances, these changes were quite instrumental in bolstering their career progression and sense of self in their work.

The work of insurance brokers, such as Carl, had experienced considerable change because the Australian government had recently introduced regulations and legislation that demand greater evidence and transparency when advising clients about insurance quotes. Each quote now requires to be documented more fully and meticulously and, therefore, takes far longer. Consequently, small insurance quotes and policies have become less attractive to Carl because of the additional work and relatively minimal return. These small quotes are now passed on to the company's clerical employees. Carl's preference is to work on high value insurance policies and provide services to large policyholders by nurturing interactions and relations with these clients, and subsequently he has directed more attention to these kinds of projects. He reports being successful in this venture. This kind of work suits well his work preferences and it is profitable. The legislated changes also directly supported him in the second half of the year in a quite different and unanticipated way. He became involved in a lawsuit in which a potential client claimed malpractice and a failure to insure a property that was subsequently destroyed by fire. However, the more meticulous record keeping required under the new legislation provided clear documentation that no agreement had been concluded. So, these changes have ultimately served Carl's interests well in terms of his preferred business focus and the capacity to add greater probity to his practice.

Recently heightened global concerns about security have done much to enhance the standing and permanency of Ken's work in the information technology unit. This work comprises establishing and maintaining informational technology-based security systems within and outside the government department for whom he works. In particular, because of his rather itinerant early working life, now his primary work goal is to secure employment that will take him through to retirement. Consequently, changes that have brought about the requirement for heightened levels of security in his department and elsewhere are assisting him achieve this goal. So a significant change in the global environment and sentiments of workplaces has served to bolster and make secure his work, and indeed elevated his work. 
In recent years, the Russian electronics engineer Lev held a technical position in a large Australian enterprise that, upon being taken over by a multinational company, had centralised its maintenance work elsewhere, thereby rendering him redundant. However, this redundancy saw him move to a more prestigious and well-paid job in a multinational transportation corporation. The downturn and crisis in the global aviation sector following the 2001 attacks on New York and Washington deleteriously affected this corporation. However, because he works in the division associated with rail transport Lev has been spared redundancy again, unlike some clerical workers whose contracts were not renewed. Moreover, the corporation shifted its focus away from aviation, and the rail transport division was given primacy, thereby securing his employment.

Lyn is a relatively new employee at the fruit and vegetable market, and is aiming to secure and develop a niche role for herself. Yet her workplace, like the other wholesale businesses in the fruit and vegetable market, tends to have high employee turnover. Changes in this workplace include staff leaving or going on holidays and a new task of exporting fruit and vegetables by airfreight to retailers in Papua New Guinea. Lyn's employment seems buoyed by her interest in, and the capacity, to undertake new tasks and those conducted by others during their periods of leave. This has been exercised through her interest in managing the export orders, which includes her becoming solely proficient in customs processes. As Lyn is in the process of seeking and forming an occupational identity based upon her work in the fruit and vegetable wholesaler, opportunities afforded by new requirements in the workplace (i.e. export orders) to bolster her place in the work team and make more secure her position are greatly welcomed.

Mike works as a supervisor in a large vehicle dealership, coordinating relations between clients and the workshops. This position exists in large part as a response to the extended warranty periods offered by automotive manufacturers to customers purchasing new vehicles. These warranties tend to wed customers to the dealership. The purchase of a new vehicle is now the beginning, not the end, of the relationship between the customer and the dealership. Nevertheless, this change has particular consequences for workshop staff. Interacting with and maintaining clients has become a key focus for dealerships because clients might purchase another new vehicle at the end of the warranty period. Mike, it seems, possesses the combination of automotive and inter-personal skills and values required to address customers' needs and coordinate work activities to support the continuity of positive relationships between the dealership and its customers. Moreover, he enjoys this kind of work as it brings together a range of professional interests associated with automotive engineering, customer service and some personal preferences about dealing with people and precision in one's work. So these changes to his work have directly served to meet his needs.

Although changes to work bring about challenges for those seeking to meet these requirements, in the case of these five workers it has also supported the continuity and development of their work-related goals. Only one participant experienced major disappointment over the twelve-months period of the study. This arose when Lev, the electrical engineer, on returning from a training course, became highly proactive and corresponded with each of three departmental heads about how his newly developed skills could transform the profitability of their departments. His invitations were treated with silent dismissal, not even acknowledgement. This suggests his agency had brushed up against and possibly contravened the workplace's regulatory practices and set himself outside of these practices. He also recounted angrily how the national human resources manager had failed to acknowledge his existence on a visit to the office where Lev worked. These incidents threatened his sense of self, and he responded accordingly. He resented the status afforded to others, such as his manager, while his own contributions went unrecognised. This may well have been the motivation for his pro-activity in promoting his 
services to senior management. Yet, his exuberant agency led not to his desired promotion, but to him being reassigned to other work duties.

In sum, against the researchers' expectations and predictions in the literature, the churning and transformations that have impacted these five individuals' work have broadly served to buttress their employment and standing. That is, changes in work assisted rather than inhibited these individuals' work goals. In at least three instances, there is a clear coincidence between their work goals and the changing requirements of their workplaces. Moreover, as discussed below, these changes permit the projection of their personal values into their work. Certainly, elsewhere in the transport corporation, for whom Lev the electronics engineer works, there have been significant job losses, career truncation and dislocations. Still, the experience of these five randomly selected participants suggests that generalised claims about changes in work leading to disempowerment, marginalisation and the generation of anxiety are not supported. Instead, a more nuanced and less prescriptive account of the relationships between changes in work and individuals' continuity and identity may be required. This account should comprise an engagement between both individual and social agency in the conduct of their work. To consider this relationship in more detail it is useful to identify the role that these individuals' identity, motivation and goals played in how they engage with changing workplaces, and how that affected their sense of selves.

\section{Identity, motivation and goals}

Interests outside their working lives were proposed by each participant to be of greater importance than their work and working lives. The insurance broker Carl emphasised the importance of his family life, his good relationship with his wife and his interest in his children and their development, and involvement in coaching junior sports teams. He noted the need for a balance between work and family life. Carl referred to some colleagues' divorces that were a product of focusing too much time and energy upon their work and neglecting their home life. Ken, the manger of the information technology unit, was quite insistent that his family and church represented the key goals towards which his work efforts were directed. This commitment was evident in the weekly tithe he pays to his church and the senior role he plays in its governance. He stated that upon retirement he would never think about his paid work. For Lev, family life, aesthetic pursuits and a small business installing security equipment were claimed as important goals beyond the corporate transport workplace in which he worked as an engineer. He directed efforts into his small business, and looked to this and his salary to generate the income he required to maintain his life-style and to educate his son. He stated that he would readily change jobs if it could secure him greater financial benefit. As a single parent, Lyn's goal for her work in the produce market was to provide more for her family through work. Her existing rental home was too noisy and she needed to move somewhere far quieter for the sake of herself and her children. She was also hoping to secure enough money to take her children on a holiday to the beach. Rather than working in the automotive dealership, Mike stated that he would much prefer to spend his time messing around with computers. His home life was claimed, in part, with working on computers and he referred to purchasing two exotic spiders, for which he cared and had established video technology links to monitor and record their lives. His home life was used to exercise other vocations. These activities were taken seriously. These, and his family, were the ends to which his work efforts were directed.

In this way, all five participants stated that life outside work was the major focus point of their lives. That is, work was not the only source of securing individuals' sense of identity and self. The participants referred to specific cultural activities, interests and communities that played a significant role in who they are, in how they see themselves, and provided evidence of the exercise of agentic action in their lives outside work. This is akin to them wanting to 'be 
themselves'. Dewey (1916) held that vocations are individuals' directions in life and not constrained to paid employment, however high or low in societal standing. The opposite of vocations, from the Deweyian perspective, is not leisure, but activity that is aimless, capricious and involves dependence upon others (Quickie, 1999). In their lives outside work, the participants demonstrated the exercise of their vocation as parents, local sport coach, church leader, technology enthusiast, entrepreneur, etc. However, Dewey (1916) argued that each of us is not restricted to just one vocation. This seemed to be the case here. Their engagement with work was premised on different goals and as such was relational.

Yet, while emphasising their life outside of work, each participant also acknowledged the significance of their working lives to their identity and sense of fulfilment: their sense of self. Commonly, each referred to being required to be competent at their work, in order to secure their employment. Each also referred to the importance of being respected as being effective and valued by their peers and other workers, and being identified as a person from whom others would seek advice and be valued for their counsel. Underlining this concern about respect were issues associated with identity and sense of self. There was also a rich intertwining between individuals' sense of self in the workplace and outside of it and that elaborated the significance of its exercise. Their work roles provided quite diverse bases for the exercise of their sense of self.

After a successful career as a professional sportsman, Carl now views himself as a successful insurance broker. He enjoys the interactions with people his work brings, the freedom to develop his clientele and contacts, to manage his own time and capacity to watch his business grow. So, aspects of his working life were claimed to be highly consistent with his sense of self and through his interactions with clients he is often able to get close to 'being himself'. Given the freedom he enjoys in his job and his indebtedness to the brokerage company in making this opportunity possible, Carl is in no hurry to achieve his ultimate goal of owning his own brokerage. Ken finds his work in the information technology unit rewarding, because it is an area of growth and employment security and stability, elements that did form part of his earlier working life. His current employment stands to provide him with engaging and well-paid work until retirement. He claims that any stable, well-paid work will suit his needs, because he does not associate his identity with work. Nevertheless, he takes pride in his efficient management of a unit within a government department, which reinforces his sense of self. So his work identity is shaped by a more general employment goal of security of employment, not the particular kind of work. His working life in the public sector is positioning him to support and direct his energies towards his church community and family. Yet, he works hard to secure this goal.

Quite openly, Lev referred to his electronic engineering work as providing him with respectable middle class status as well as the financial freedom that a good salary provided for him and his family. That is, the professional standing of his work afforded him a particular level of status in the community that is regulated by his occupational identity. Since arriving in Australia, Lev has worked agentically and intentionally to become proficient in English and realise fully the application of his electronics knowledge in well-paid, high status and productive employment. However, this came only after a period of engaging in menial work roles, constrained by his poor English language. His current job provides a sense of self that is more closely aligned to 'being himself' insofar as it represents a step towards the ideal he is trying to achieve: that is, higher levels of remuneration, autonomy and discretion at work. Nevertheless, he remains frustrated at not being able 'to be himself' in his approach to work and his conduct in the workplace, his dress and work habits have been questioned. He also feels under-utilised in his current position and believes he has the capacity to contribute more and is deserving of much higher remuneration and better conditions. Also, he regrets his work has not provided close friendships with his colleagues. For Lev, positive relationships with others are an important part 
of his identity and sense of being. Elsewhere, he realises these through socialising in the local Russian émigré community. This suggests a sense of work identity and agency that is strong, yet frustrated by a lack of potential fulfilment, acknowledgement and respect. In short, through not being allowed to 'be himself', Lev feels his 'sense of sense' is threatened.

For Lyn, work in the fruit market provides an opportunity to demonstrate a capacity to perform roles, other than being the caregiver to her children, outside of the home. She consistently reported having a strong sense of industry and organisation, and a desire to build a further financial foundation for herself and her children. These intentions were the basis of her being energetic and proactive in her work, 'being herself'. Becoming a paid worker and having sole responsibility for an area of work seems to fulfil an urgent need to re-affirm her identity outside the home. Her intentionality and agency here was evident throughout the yearlong period of the interviews. In the first interview, she expressed an interest in becoming proficient in the purchasing and transportation of fresh herbs. This arose from an opportunity in previous employment. By the second interview, her intentions and agency were being directed to another opportunity, being responsible for export orders. This requires understanding and responding to quarantine and custom requirements in which she alone was knowledgeable. As the year progressed she reported and was observed as having established herself well within the workplace, not only in a further specialist role, but also as a keen, proactive and reliable worker. Her intention was to become indispensable in the workplace and she pursued this agentically and with some success. She was buoyed by the owners' positive comments and gestures towards her and offers of additional work. Towards the end of the interviews, she had been offered a job to manage a plant nursery in an attractive coastal city about 100 kilometres north of where she lived and worked. Surprisingly, given her stated goals, she refused this offer. It also offered a living environment quite different from the one in which she had expressed constant dissatisfaction. However, the intertwining between her work and home lives may have influenced this decision. Such a move would disrupt her children's lives, she claimed. Also, she had met a man who operated a forklift at the fruit market, and they became engaged. So while exercising her agency in establishing herself within the workplace, there is also an intertwining between the workplace and her life outside of work, which in this case sought to reject a job offer that seemed to meet other of her stated intentions.

At the commencement of the interviews, Mike was experiencing difficulties with another supervisor in the automotive dealership over who had line authority within the workshops. This conflict threatened his commitment to the workplace. Subsequently, it was reported that this matter had been resolved in his favour. Then, despite claiming his home interests were the primary ones, he began to spend more and more time at his workplace. He went in early and came home late, sometimes driving to and from work in a car that had a persistent or difficult fault to diagnose. In earlier interviews, he claimed to have no career ambitions beyond his current supervisory position. There were more important things to do with his time. However, by the later interviews he had changed his mind. He noted his intention to apply for a more senior position in the future. A key purpose for Mike's practice in the dealership is to provide service to others, in which he found satisfaction and personal fulfilment. He referred back to his earlier career as a mobile service operator assisting stranded motorists, often holidaymakers, whose vehicles had broken down. He reported satisfaction in being able to assist these individuals and minimise disruption to their holidays. In this way, his new role in providing a high level of service is consistent with key personal intentions and subjectivities; of 'being himself'.

In these ways, the process of self-construction for each of these workers relates to and represents an entwining or interweaving of both working life and that outside of it; this is reflected in seeking to secure the self, and possibly 'be themselves'. The degree of relative or 
particular importance of 'being themselves' differs across these individuals and possibly fluctuates over time as particular events or priorities arise in their lives. For instance, Ken is not interested in securing his self through work in the public sector information technology role, although he wants to exercise a 'sense of self'. Yet, he is not alone. Common to all participants was a strong desire to exercise their sense of self in the workplace; and where possible for these individuals to 'be themselves', which encompassed both life inside and outside work, which is edging closer to the humanistic conception that O’Doherty and Willmott (2001) so strongly deny. There were differences between the role work plays for male and female participants.

However, for each of the five individuals, work relates to their identity: they are identified as an engineer, supervising mechanic, effective worker, diligent and trusted insurance broker and manager. Moreover, all five participants were able to exercise in part personal agency. If the exercise of individual agency through personally fulfilling activities is a measure of the link between individuals' identity and their work, it might be concluded that all five individuals were exercising their 'sense of self' and engaged willingly and interdependently in their work. That is, part of their identity and construction of self and the exercise of agentic action is being directed and remade through interdependence with their work. This sentiment reflects what Pusey (2003) concludes is the role of work for middle Australia: "For nearly everyone work is a social protein, a buttress for identity and not a tradeable commodity" (p.2). Each participant referred to the importance of being able to exercise their agency in their work activities. Perhaps Lev over exercised his. Whether it was the ownership of the work undertaken, the possibilities of trying to do new things, being able to manage oneself, being able to exercise standards of work and discretion that reflect individual goals, or the exercise of personal licence, the significance of the exercise of agency was amplified by each informant. So while, they claimed work not to be as important as their life outside work, the evidence holds that these five workers' sense of self as something negotiated, shaped and sustained in the workplace.

All this suggests the significance of agentic action in assisting and directing individuals to exercise their 'sense of self' through their work, with a goal beyond that of being able to 'be oneself', albeit through work or life outside work. Moreover that sense of self changes over time and through negotiation with work. Somerville notes how aged care workers often engage in aged care work through convenience, rather than particular interest (Billett \& Somerville, 2004). However, once engaged in this work they form identities as aged care workers and even carry emblematic back injuries of aged care workers with pride (Somerville \& Bernoth, 2001). In this way, the transformation of self arises through engagement and negotiation with their work, as was the case with Lyn.

\section{Self, agency and learning at work}

In conclusion, through the intertwining of work and life outside of work, these individuals are held to exercise a sense of self in efforts to 'be themselves' and, therefore, in how they engage in and what they learn through work and throughout working life. For some of the participants this was more readily achievable than for others. For Ken, his family and church community and relative lack of interest in the specific focus of his work meant that workplace conflicts were less significant to him than for Lev, for instance. So although both these individuals worked in large organisations that exercised regulatory practices (Bernstein, 1996) they were relational, seemingly having less impact upon Ken, the public servant, than upon Lev, the disgruntled electronics engineer. Ken was able to work around a new boss's agenda, for instance. Lev's sense of self seemed more violated by having his suggestions and existence being summarily dismissed. In these two cases, employees in large organisations prescribe a set of rules that regulate employees' behaviour and relationship towards others; their regulatory practices. True, the practices were not as prescribed as others have recorded (e.g. Grey, 1994). However, what is 
amplified in this study is how these individuals' sense of selves influences how, and for what purposes, they engage with work, and how they negotiate their sense of self accordingly, as exemplified by Lev and Ken’s distinct responses.

Against some predictions and the researchers' expectations about changes adversely affecting workers, it was found that change for these five workers had either buttressed or facilitated their standing in the workplace and their vocational goals. While all five participants claimed that their working life was merely a means to an end, the evidence suggests their identities, agentic actions and subjectivities were exercised in their work in consideration of securing their 'sense of selves'. By different degree, there was evidence of interdependence and intertwining between their work and life outside work. In particular, it seemed that these individuals' capacity to exercise their agency at work was strongly associated with how they valued that work and identified with it as permitting them to exercise a 'sense of self'. It reflected how they might exercise their efforts in participating in and learning through their working life.

This suggests that for lifelong learning to be successfully enacted consonance between the qualities of work and individuals' identity and interests may be required. Otherwise, there would be a contested ongoing negotiation between individuals' sense of self and the goals of the work practice. What the evidence suggests here is that because of these negotiations, the humanistic and perhaps unlikely goal of 'being themselves' may not always be possible to drive individuals' intentions and agentic action at work. However, for individuals to exercise a 'sense of self' in their work, they need to go on engaging in ways that sees the attainment of their interests and intentions. The consonance between individual and workplace goals that are identified in the study may well lead to unreflective, uncritical and limited learning outcomes. The sense is that, in some ways, Lev has had the richest of learning experiences. While not fully accounted for in Wertsch's (1998) account of appropriation and mastery, Lev's contestation with the corporate workplace had likely generated rich learning for him, albeit not the kind of learning he intended. At the commencement of the interviews he celebrated living and working in Australia, because he could exercise his agency and intents to their full in ways not possible in Russia. By the final interview, his sense of self and, perhaps overly idealistic, views about his adopted country were being tested. This suggests that learning throughout working life arises as much from dissonance, as cognitivists have long claimed, than through appropriation where shared values exist between the learner and the social practice.

Hence, in conclusion, it seems that from this small study that there is a need to consider lifelong learning in terms of individuals' drive towards securing a 'sense of self' and 'being themselves', both in their work and lives outside of work. Therefore, the quest of achieving the ambitious government, industry and enterprise goals of lifelong learning should be directed as much by individuals and thier identities and goals, as by government and employers. The mobilisation of the self will be likely realised in ways that are commensurate with the self, and directed towards individuals 'being themselves'.

The author acknowledges the research assistance provided by Ray, Dimitri and Margarita in the original study. Also, the contributions of Alan Brown and Simone Kirpal assisted the revision of the chapter. This research was funded through the small grants scheme of the Australian Research Council. 


\section{References}

Archer, M. S. (2000). Being Human: the problem of agency. Cambridge: Cambridge University Press.

Baldwin, J. M. (1894). Personality-Suggestion. Psychological Review, 1, 274-279.

Bauer, J., Festner, D., Gruber, H., Harteis, C., \& Heid, H. (2004). The effects of epistemological beliefs on workplace learning. Journal of Workplace Learning, 16(5), 284-292.

Bauman, Z. (1998). Work, consumerism and the new poor. Buckingham: Open University Press.

Beck, U. (1992). Risk Society: Towards a new Modernity (M. Ritter, Trans.). London: Sage.

Berger, P. L., \& Luckman, T. (1967). The Social Construction of Reality. Harmondsworth, Middlesex: Penguin Books.

Bernstein, B. (1996). Pedagogy, Symbolic Control and Identity: Research Critique. London: Taylor and Francis.

Billett, S. (2000). Defining the demand side of VET: Industry, enterprises, individuals and regions. Journal of Vocational Education and Training, 50(1), 5-30.

Billett, S. (2001). Learning in the workplace: Strategies for effective practice. Sydney: Allen and Unwin.

Billett, S. (2003a, 1-3 December 2003). Individualising the social - socialising the individual: Interdependence between social and individual agency in vocational learning. Paper presented at the 11th Annual International conference on post-compulsory education and training: Enriching learning cultures, Gold Coast.

Billett, S. (2003b). Sociogeneses, Activity and Ontogeny. Culture and Psychology, 9(2), 133-169.

Billett, S. (2005a). Constituting the workplace curriculum. Journal of Curriculum Studies, 37(1).

Billett, S. (2005b). Relational interdependence between social and individual agency in work and working life. Mind, Culture and Activity, 12(4).

Billett, S., Smith, R \& Barker, M. (2005) Understanding work, learning and the remaking of cultural practices. Studies in Continuing Education 27 (3)

Billett, S., Barker, M., \& Hernon-Tinning, B. (2004). Participatory practices at work. Pedagogy, Culture and Society, 12(2), 233-257.

Billett, S., \& Somerville, M. (2004). Transformations at work: Identity and learning. Studies in Continuing Education, 26(2), 309-326.

Billett, S. \& Pavolva, M (2005) Learning through working life: self and individuals' agentic action. International Journal of Lifelong Education. (24) 3 195-211

Brunello, G., \& Medio, A. (2001). An explanation of International Differences in Education and Workplace Training. European Economic Review, 45(2), 307-322.

Dewey, J. (1916). Democracy and Education. . New York: The Free Press.

Edwards, R., \& Boreham, N. (2003). 'The centre cannot hold': complexity and difference in European Union policy towards a learning society. Journal of Educational Policy, 18(4), 407-421.

Erikson, E. H. (1968). Identity, Youth and Crisis. New York: Norton.

Field, J. (2000). Governing the ungovernable: why lifelong learning promises so much yet delivers so little. Educational Management and Administration, 28(3), 249-261.

Gergen, K. J. (2000). The Saturated Self: Dilemmas of Identity in Contemporary Life. New York: Basic Books.

Green, F. (2001). Its been a hard day's night: The concentration and intensification of work in the late Twentieth Century Britain. British Journal of Industrial Relations, 39(1), 53-80.

Grey, C. (1994). Career as a project of the self and labour process discipline. Sociology, 28(2), 479-497.

Hodkinson, P., \& Hodkinson, H. (2003). Individuals, Communities of Practice and the Policy Context. Studies in Continuing Education, 25(1), 3-21. 
Malle, B. F., Moses, L. J., \& Baldwin, D. A. (2001). Introduction: The Significance of Intentionality. In B. F. Malle, L. J. Moses \& D. A. Baldwin (Eds.), Intentions and Intentionality: Foundations of Social Cognition (pp. 1-26). Cambridge, Massachusetts: The MIT Press.

Newman, D., Griffin, P., \& Cole, M. (1989). The construction zone: Working for cognitive change in schools. Cambridge: Cambridge University Press.

Noon, M., \& Blyton, P. (1997). The realities of work. Basingstoke, Hants: Macmillan.

O'Doherty, D., \& Willmot, H. (2001). The question of subjectivity and the labor process. International Studies of Management and Organisation, 30(4), 112-133.

Piaget, J. (1968). Structuralism (C. Maschler, trans. and ed.). London: Routledge \& Kegan Paul.

Pusey, M. (2003). The Experience of Middle Australia. Cambridge, UK: Cambridge University Press.

Quickie, J. (1999). A curriculum for life: Schools for a democratic learning society. Buckingham: Open University Press.

Ratner, C. (2000). Agency and culture. Journal for the Theory of Social Behaviour, 30(413-434).

Rifkin, J. (1995). The end of work: The decline of the global labor force and the dawn of the post- market era. New York, NY: Ajeremy P. Tarcher/ Putnam Book, G.P. Putnam's Sons.

Rogoff, B. (1990). Apprenticeship in thinking - cognitive development in social context. New York: Oxford University Press.

Rose, N. (1990). Governing the soul: The Shaping of the Private Self. London: Routledge.

Scribner, S. (1985). Vygostky's use of history. In J. V. Wertsch (Ed.), Culture, communication and cognition: Vygotskian perspectives (pp. 119-145). Cambridge, UK: Cambridge University Press.

Smith, R. J. (2004). Necessity in action: The epistemological agency of the new employee. Unpublished Master of Education, Griffith University, Brisbane.

Somerville, M. (2002). Changing Masculine Work Cultures. Paper presented at the Envisioning practice -- Implementing change, Gold Coast.

Somerville, M., \& Bernoth, M. (2001). Safe Bodies: Solving a Dilemma in Workplace. Paper presented at the Knowledge Demands for the New Economy. 9th Annual International Conference on Post-compulsory Education and Training., Gold Coast, Queensland.

Valsiner, J. (1998). The Guided Mind: A Sociogenetic Approach to Personality. Cambridge, Mass: Harvard University Press.

Valsiner, J., \& van der Veer, R. (2000). The Social Mind: The construction of an idea. Cambridge, UK: Cambridge University Press.

von Glasersfeld, E. (1987). Learning as a constructive activity. In C. Janvier (Ed.), Problems of representation in the teaching and learning of mathematics. Hillsdale, NJ: Lawrence Erlbaum.

Wertsch, J. V. (1998). Mind as Action. New York: Oxford University Press.

Wright Mills, C. (1973). The meaning of work throughout history. In F. Best (Ed.), The future of work. Englewood Cliffs, NJ: Prentice Hall. 